\title{
Análise Epidemiologica da Esquistossomose Mansonica no Municipio de Bacuri (Área Endêmica da Baixada Ocidental do Estado do Maranhão - Brasil) entre 2011 e
}

\section{0}

\author{
Epidemiological Analysis of Schistosomiasis Mansonica in the Municipality of Bacuri (Endemic
}

Area of the western lowland of the State of Maranhão - Brazil) between 2011 and 2020

Análisis Epidemiológico de la Cistosomiasis Mansonica en el Municipio de Bacuri (Zona Endémica

del Centro Occidental del Estado de Maranhão) entre 2011 y 2020

Recebido: 12/10/2021 | Revisado: 19/10/2021 | Aceito: 25/10/2021 | Publicado: 28/10/2021

\author{
Cristina Limeira Leite \\ ORCID: https://orcid.org/0000-0002-7321-1496 \\ Universidade Federal do Estado do Rio de Janeiro, Brasil \\ E-mail: crislimeira@gmail.com \\ Iraciane Rodrigues Nascimento Oliveira \\ ORCID: https://orcid.org/0000-0001-6535-5396 \\ Universidade Federal do Maranhão, Brasil \\ E-mail: iraciane.rodrigues@gmail.com \\ Maria Rita Sodré Oliveira \\ ORCID: https://orcid.org/0000-0001-9950-6332 \\ Universidade Federal do Maranhão, Brasil \\ E-mail: mariaritasodreoliveira9@gmail.com \\ Analyta Rodrigues Severo \\ ORCID: https://orcid.org/0000-0002-7583-5147 \\ Universidade Federal do Maranhão, Brasil \\ E-mail: enf.analytasevero@gmail.com \\ Christina Wyss Castelo Branco \\ ORCID: https://orcid.org/0000-0002-0509-171X \\ Universidade Federal do Estado do Rio de Janeiro, Brasil \\ E-mail: cbranco@unirio.br
}

\begin{abstract}
Resumo
A esquistossomose mansônica é considerada um problema de saúde pública, onde, além de provocar diversos agravos a saúde, tem levando muitas pessoas a morte. Situação evidenciada em diversos municípios brasileiros, onde as pessoas possuem hábitos de vida que as expõem diariamente aos agentes causadores da esquistossomose. O objetivo deste trabalho foi investigar a epidemiologia da esquistossomose mansoni no Município de Bacuri-Ma. Trata-se de um estudo epidemiológico retrospectivo descritivo do tipo documental, com abordagem quali-quanti. Os dados foram obtidos, nas bases de dados do Programa Especial de Controle da Esquistossomose e da Fundação Nacional de Saúde (FUNASA) do município de Bacuri-Ma, dentro de um recorte temporal de dez anos (2011 a 2020). O município estudado, como vários do estado do Maranhão, apresentou alta prevalência e incidência para esquistossomose, já que diante de uma média de $30 \%$ da população avaliada, obteve-se uma incidência média de 17,8 \% de positividade.
\end{abstract}

Palavras-chave: Esquistossomose; Epidemiologia; Saúde pública; Baixada do Maranhão.

\begin{abstract}
Schistosomiasis mansoni is considered a public health problem that, besides causing several health problems, has led many people to death. In several Brazilian municipalities, the local population is exposed to causative agents of schistosomiasis, being the diagnosis and treatment of paramount importance. The aim of this study was to investigate schistosomiasis' epidemiology in the Municipality of Bacuri-MA, located in an area considered as endemic. This is a descriptive retrospective epidemiological study of documentary type, with a quali-quantitative approach, with data collection between 2011 and 2020. The municipality had a high prevalence and incidence of schistosomiasis, since from an average of $30 \%$ of the population evaluated, the average incidence of positivity was $17.8 \%$. There was evidence of a temporal increase trend for the percentage of positive locations for schistosomiasis, an increase in the number of people to be treated and an increase in the number of untreated people over the years.
\end{abstract}

Keywords: Schistossoma mansoni; Epidemiology; Public health; Lowland of Maranhão. 


\section{Resumen}

La esquistosomiasis mansoni se considera un problema de salud pública, donde, además de causar varios problemas de salud, ha provocado la muerte de muchas personas. Situación evidenciada en varios municipios brasileños, donde las personas tienen hábitos de vida que los exponen diariamente a los agentes causantes de la esquistosomiasis. El objetivo de este trabajo fue investigar la epidemiología de la esquistosomiasis mansoni en Bacuri-Ma. Se trata de un estudio pidemiológico descriptivo retrospectivo de tipo documental, con enfoque cuali-cuanti. Los datos se obtuvieron de las bases de datos del Programa Especial para el Control de la Esquistosomiasis y la Fundación Nacional de Salud (FUNASA) en el municipio de Bacuri-Ma, en un período de tiempo de diez años (2011 a 2020). El municipio estudiado, como muchos en el estado de Maranhão, tuvo una alta prevalencia e incidencia de esquistosomiasis, ya que frente a un promedio del $30 \%$ de la población evaluada, hubo una incidencia media de 17,8\% de positividad.

Palabras clave: Schistossoma mansoni; Esquistosomiasis; Epidemiología; Salud pública; Tierras bajas de Maranhão.

\section{Introdução}

A esquistossomose mansônica é uma doença infecciosa parasitária, causada pelo trematódeo Schistosoma mansoni, que tem como hospedeiros intermediários caramujos de água doce do gênero Biomphalaria que acomete, em geral, indivíduos de menor poder aquisitivo, que vivem em áreas com maior deficiência de infraestrutura. A esquistossomose no mundo teve os primeiros registros nas bacias dos rios Nilo, na África, e do Yangtzé, na Ásia, sendo ovos de Schistosoma obtidos em vísceras de múmias egípcias, remontando a origem a 1.250 A. C. Em 1852 no Cairo, pela primeira vez, Theodor Bilharz constatou em autópsia em veias mesentéricas os helmintos que ficaram conhecidos como "esquistossomos". Daí o nome de "bilharziose" ou "bilharzíase" como sinonímia para esquistossomose (Brasil, 2014).

No Brasil, a introdução da esquistossomose acompanhou o tráfico de escravos originários da costa ocidental da África, vindos para trabalhar nas lavouras de cana-de-açúcar, tendo a parasitose se expandindo inicialmente pelo nordeste brasileiro. Atualmente, a esquistossomose apresenta-se como uma das doenças tropicais negligenciadas e de maior relevância no cenário geral da saúde pública no país, registrando maiores taxas de prevalência na região nordeste (Brasil, 2014; Brasil, 2018).

No Maranhão, a doença traz um histórico de mais de um século, sendo sua primeira notificação em 1920 no município de São Luís. Porém, registros da enfermidade no Estado vem desde o século XVI, com a vinda dos escravos da Angola e Guiné, tendo sido utilizada a mão de obra desses escravos, principalmente na Baixada Ocidental do Maranhão para o cultivo de algodão, arroz, mandioca e cana-de-açúcar, estabelecendo a agricultura como atividade local (Lira et al., 2017).

Após as primeiras notificações, houve a preocupação com instalação e expansão rápida da doença e, em 1977, buscou-se medidas para o controle da doença que foi o Programa Especial de Controle da Esquistossomose (PECE). Este programa consiste em atividades direcionadas ao tratamento dos indivíduos infectados sendo utilizado método de quimioprofilaxia com oxaminiquine havendo uma redução da doença, porém não sua erradicação (Carvalho, 2014).

A esquistossomose mansônica é considerada um problema relevante de saúde pública, já que além de provocar diversos agravos a saúde, tem levado muitas pessoas a morte, sendo muitas vezes negligenciada pelo poder público. Tal fato é evidenciado em diversos municípios brasileiros, em áreas de maiores incidências, onde as pessoas possuem hábitos de vida que as expõem diariamente aos agentes causadores da esquistossomose.

Segundo Brito; Silva; Quinino (2020), a esquistossomose, ainda é considerada como um problema de saúde pública em diversas regiões do Brasil, sendo que em 2017 acometeu, cerca de 1,5 milhão de pessoas em todo país. Destas, 80\% foram identificadas na região Nordeste, estados de Minas Gerais e Rondônia e norte do Estado do Paraná. Segundo dados do Sistema de Informação do Programa de Controle da Esquistossomose (SISPCE), no período de 2009 a 2019, "o percentual de positividade para S. mansoni nas áreas endêmicas apresentou variações de positividade de 5,20\% em 2009 e 2,90\% em 2018". Sendo realizados em torno de 9.867.120 exames e detectados 423.117 casos e um percentual médio de positividade de 4,29\% (Brasil, 2021). 
O tempo de vida média do S. mansoni no organismo humano é de 5 anos, sendo que alguns parasitas conseguem viver por mais de 30 anos no organismo humano, liberando ovos nas vênulas terminais do plexo mesentérico. Normalmente, os ovos expelidos pelo ser humano simultaneamente com as fezes, ajudam a perpetuação do ciclo vital do parasita, sempre que as condições adequadas do meio ambiente às cercarias estiverem presentes. Os ovos que não são eliminados, geram minúsculos granulomas e nódulos cicatriciais nos órgãos em que se alojam, na maioria das vezes, nas paredes do intestino ou no fígado, podendo provocar formas ectópicas em qualquer órgão ou tecido do organismo humano (Sousa, 2011).

Segundo Sistema de Informações de agravos e Notificação (SINAN), "Inicialmente, a doença possui característica assintomática, podendo evoluir para casos clínicos gravíssimos e levar o paciente a óbito". Os sintomas vão desde dermatite cercariana, hipertensão pulmonar e portal, ascite, ruptura de varizes do esôfago, problemas hepatointestinal caracterizado pela presença de diarreias e epigastralgia às complicações mais graves como hepatoesplenomegalia e hipertensão, que podem levar o paciente à morte (Fratini; Saupe; Massaroli, 2008).

Ainda, a esquistossomose hematóbia, comum nos países africanos, ademais as formas ectópicas neurológicas da doença são bastante graves, podendo ser medular, também chamada de mielopatia esquistossomótica ou esquistossomose medular ou cerebral, que atingem o cérebro (Fratini; Saupe; Massaroli, 2008). O diagnóstico precoce é importante para prevenir desde as formas simples as formas graves da doença, uma vez que através do exame colposcópico utilizando o método de Kato-Katz, é possível a identificação da quantidade de ovos por amostra.

Sob um aspecto geral, a maior parte dos problemas relacionados à esquistossomose mansoni, estar relacionada a populações carentes com saneamento básico precário e desprovidas de água potável, tirando dos mananciais impróprios a água para sua subsistência e da falta de informação da população quanto às formas de transmissão e prevenção. Assim, torna-se necessário ações visando o diagnóstico e tratamento, evitando avanço para as formas crônicas. Uma vez diagnosticado, o tratamento se dá através de medicamentos específicos, que agem na cura da infecção. Atualmente, são utilizados dois medicamentos no tratamento, tanto de crianças como de adultos: o praziquantel e a oxaminiquina, sendo o primeiro o mais utilizado (Silva; Neto \& Silva, 2021).

Apesar das melhorias no quadro epidemiológico da esquistossomose no Brasil, o país ainda é o mais afetado nas Américas. Estados no nordeste do Brasil apresentam um longo histórico de pessoas infectadas pelo S. mansoni, e apresentam a maior prevalência desta parasitose (Cruz; de Salazar; La Corte, 2020). Atualmente, o foco da doença ocorre em cerca de 26 municípios do Maranhão, sendo área endêmica a Baixada Ocidental Maranhense, pelas áreas com cobertura por vegetação, sendo favoráveis para reprodução dos caramujos transmissores, das espécies Biomphalaria glabrata e Biomphalaria straminea. A grande exposição as cercarias do S. mansoni acontece também pela população utilizar desses campos hídricos para lazer e trabalho. Os moradores em sua maioria estão associados a pesca, caça e uso como meio de transporte cavalos, jegues e jumentos nos campos de vegetação tendo contato direto com agente transmissor (Cantanhede, 2015).

São Luís é o município com mais bairros sinalizados como endêmicos para esquistossomose, justificado pela ocupação irregular nos bairros, sendo marcada pela migração da população da Baixada Ocidental do Maranhão, que vivem em más condições de vida em localidades dessa região. Além das condições citadas, o clima úmido presente na região, com chuvas sazonais aumenta a infecção e a disseminação do parasita pela água infectada que transita nos bairros, contaminando a população facilmente (Carvalho, 2014). A expansão e permanência da condição endêmica é favorecida principalmente pela região ser marcada pela falta de saneamento básico, água potável e coleta adequada de lixo. Vale ressaltar os aspectos sociais e culturais dessa região, que têm como características baixa escolaridade, agricultura como fonte de renda e idade avançada, ocasionando o conhecimento insuficiente para medidas de higiene eficazes. Dentro disso, a transmissão torna-se altamente proliferativa, trazendo limitações para população infectada (Holanda, 2020).

Estudos epidemiológicos com foco específico na esquistossomose, se fazem necessário, uma vez que através dessas 
pesquisas, tem-se uma aproximação com a realidade vivenciada nos municípios, trazendo assim subsídios para implementação de ações e estratégias que venham a combater esta parasitose. Com esse enfoco, o objetivo do presente trabalho é o de investigar a epidemiologia da esquistossomose mansoni no Município de Bacuri, localizado no litoral norte do Maranhão. Trata-se de uma pesquisa epidemiológica retrospectiva descritiva do tipo documental, e tendo como abordagem qualitativa e quantitativa. Quanto aos procedimentos metodológicos de coleta de dados, as informações se deram a partir de buscas em documentos oficiais nas bases de dados do PCE e nas bases de dados da Fundação Nacional de Saúde (FUNASA) do município de Bacuri-Ma, dentro de um recorte temporal de dez anos (2011 a 2020).

Espera-se que os resultados, auxiliem possíveis intervenções nas estratégias de levantamento epidemiológico no município de Bacuri. Por outro lado, espera-se incentivar ações no que se refere ao saneamento básico, esgoto e investimento em água tratada, e assim, dirimir essa problemática vivenciada pelos munícipes, obtendo então uma melhor qualidade de vida. O presente trabalho será de grande relevância para os profissionais da área da saúde, pois diante da pesquisa proposta, tais profissionais poderão utilizar o estudo como uma ferramenta de planejamento de saúde, tornando possível uma sistematização mais eficaz e resolutiva. Entende-se ainda que, servirá para a população investigada, pois mediante os dados apresentados, os indivíduos envolvidos terão melhor esclarecimento sobre a esquistossomose mansoni e com isso possam adotar uma nova postura com relação aos riscos a que estão expostos, importância do diagnóstico e tratamento da parasitose.

Tendo como primeira hipótese a de que o município de Bacuri é uma área endêmica para a esquistossomose, e a segunda hipótese a de que a maioria das localidades apresenta casos positivos para esta parasitose, o objetivo geral do presente estudo foi investigar a epidemiologia desta parasitose nas localidades deste município. Tivemos como objetivos específicos: i) avaliar o percentual da população pesquisado para a parasitose, ii) estimar a prevalência e incidência da esquistossomose na região em estudo; iii) avaliar a prevalência da esquistossomose entre as verminoses, iv) estimar o percentual de pessoas tratadas, v) avaliar a evolução ao longo dos anos da epidemiologia da esquistossomose no município.

\section{Metodologia}

\section{1 Área de Estudo: o Município de Bacuri}

\subsubsection{Origem, aspectos econômicos e demográficos}

O município de Bacuri está inserido na mesorregião Norte maranhense, Microrregião Litoral Ocidental maranhense (Fig. 2). Localiza-se na Baixada Ocidental Maranhense (142' 14" S e 457'45"O), a noroeste da Ilha de São Luís (Upaon-Açu), a 33 metros de altitude, abrangendo uma área de $789,9 \mathrm{~km}^{2}$. Os primeiros habitantes de Bacuri foram os indígenas, depois vieram os portugueses e africanos. Bacuri foi colonizado a partir do mar, uma vez que sua localização se dá entre as cidades de Turiaçu e Cururupu. Devido à formação de povoados as margens do continente e com o crescimento dessas cidades, Bacuri se tornou um ponto de hospedagem para os viajantes que por ali passavam e posteriormente um polo comercial de trocas, que foi se consolidando a partir dos anos 30 e 40 (Bacuri, 2020).

O nome do município se deve ao bacurizeiro (Platonia insignis), uma árvore popular na região amazônica, explorada por ter uma madeira resistente para construção de embarcações, casas e produzir o fruto bacuri, apreciado pelo sabor e utilizado como iguaria. Apesar de levar o nome de Bacuri, a cidade não é uma grande exportadora da fruta, pois as principais atividades econômicas do município são a agricultura e a pesca (Cardoso, 2001). Na agricultura tem se o destaque para a produção de arroz, milho, feijão, cana-de-açúcar e mandioca. Além dessas inclui ainda o babaçu, buriti e a juçara, na agricultura de subsistência, e na pesca destaca-se a exportação de camarões (Bacuri, 2020).

Economicamente, o Município de Bacuri apresenta um PIB per capita de R \$ 5.320,40 e IDHM de 0,578, ocupando a posição 208 de 2017 em relação aos outros municípios do estado do Maranhão. Cerca de 52,27\% da população reside na zona urbana, sendo que a incidência de pobreza no município e o percentual dos que estão abaixo do nível de pobreza é de 62,29\% e 
51,97\% respectivamente (IBGE, 2010). A taxa de mortalidade infantil média na cidade é de 16.46 para 1.000 nascidos vivos. Comparado com todos os municípios do estado, fica nas posições 91 de 217. Na educação apresenta uma taxa de escolarização de 6 a 14 anos de idade de 97,8\% (IBGE, 2010).

Conforme o último censo do IBGE o Município de Bacuri possui uma população de aproximadamente 16.604 mil habitantes e uma densidade demográfica de 23,6 habitantes $/ \mathrm{km}^{2}$. A densidade demográfica no território do município de Bacuri é de 21,07 habitantes por $\mathrm{km}^{2}$ (IBGE, 2010). Possuindo um dos IDH mais baixo de todo Estado 0,578. Apesar de contar com rede de abastecimento geral de água (66\%), a população de áreas urbanas de Bacuri conta com 0\% de rede de esgotamento sanitário, sendo utilizados outro escoadouro (27\%), fossa rudimentar (36\%), e valas (19\%) (IBGE, 2010).

Figura 1. a) Região Nordeste com indicação da área no Estado do Maranhão onde se localiza o Município de Bacuri. b) Limites do Município de Bacuri.

a)

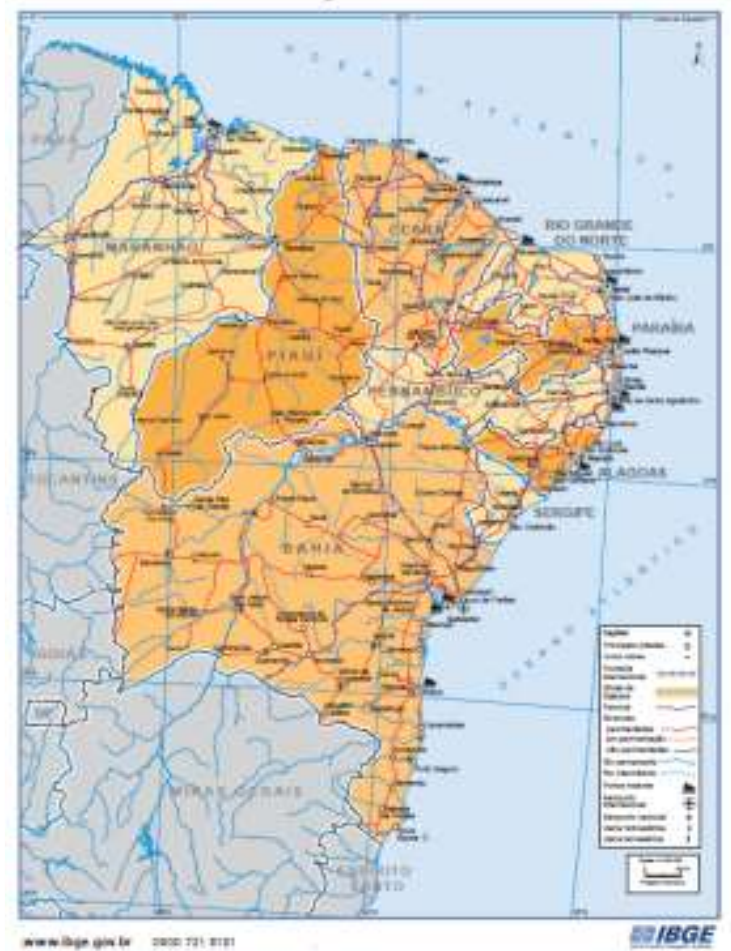

b)

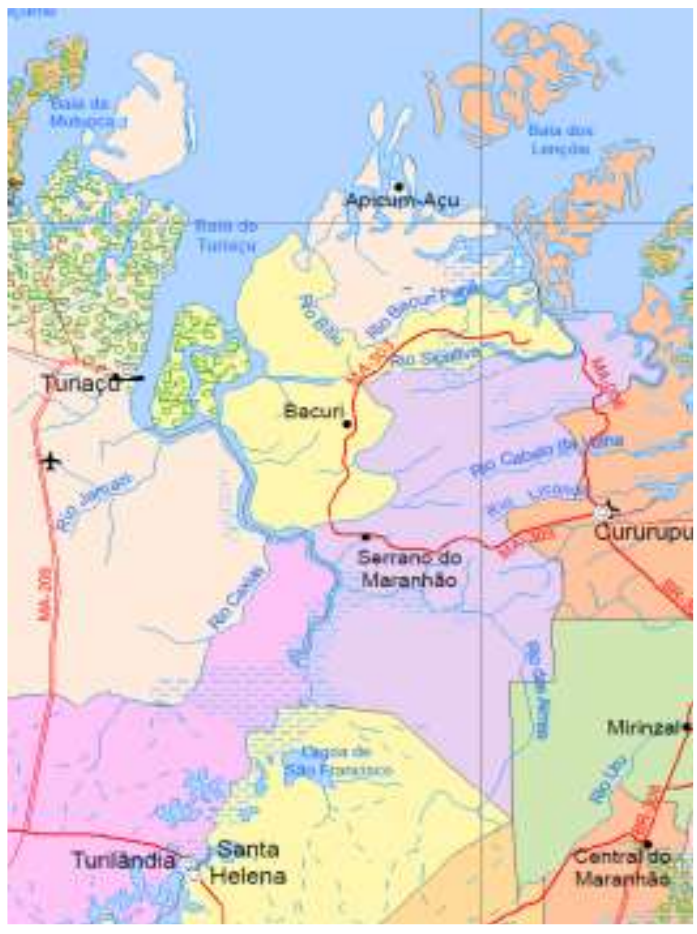

Fonte: IBGE (2010).

\subsubsection{Aspectos fisiográficos}

O Munícipio de Bacuri, com território pertencente ao bioma Amazonia, apresenta clima quente e úmido, típico dos padrões de clima tropical e equatorial, com períodos bens distintos de chuvas que vai de janeiro a junho, e período de seca/estiagem, que compreende os meses de julho a dezembro, conhecido como períodos de "inverno" e "verão", e variação térmica entre $25^{\circ} \mathrm{C}$ e $27^{\circ} \mathrm{C}$ (Mochel, 1999).

Em relação às características geofísicas do munícipio inclui a presença de diversos ecossistemas como manguezais, apicuns, matas de várzeas, campos de várzeas e terra firme (Fig. 2), utilizados pela população local para sua subsistência. Os manguezais são ecossistemas costeiros, sujeitos a inundações periódicas pelas marés e águas doces, associados às margens de baías, enseadas, desembocaduras rios e reentrâncias costeiras (Mochel; Cutrim; Gueiros, 2000). Os apicuns são zonas de transição entre o médio e o supralitoral, caracterizado pela hipersalinização, decorrentes da evaporação da água das marés e depósito dos cristais de sódio, o que torno o solo rachado, além de ser areno-argiloso, não possui vegetação, e a única forma de 
vida são as cianobactérias.

Figura 2. a) Presença de manguezais, apicuns, matas de várzeas, b) campos de várzeas e terra firme no Município de Bacuri.

a)

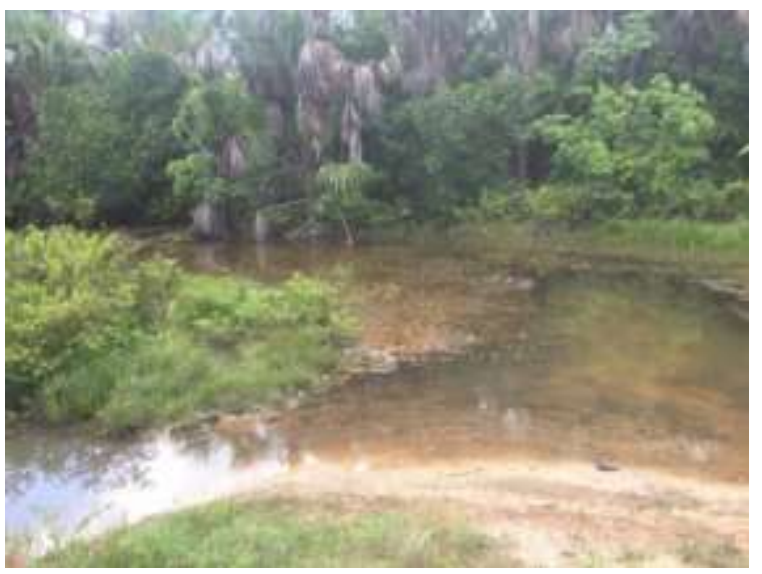

b)

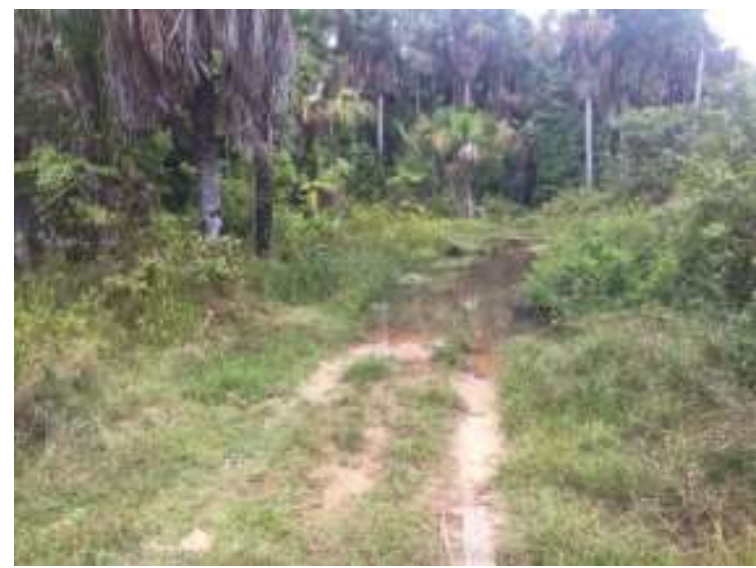

Fonte: Autores.

Figura 3. a) Matas de várzeas com presença de plantações típicas de áreas inundadas; b) Zona Urbana com predominância de áreas de mata.

a)

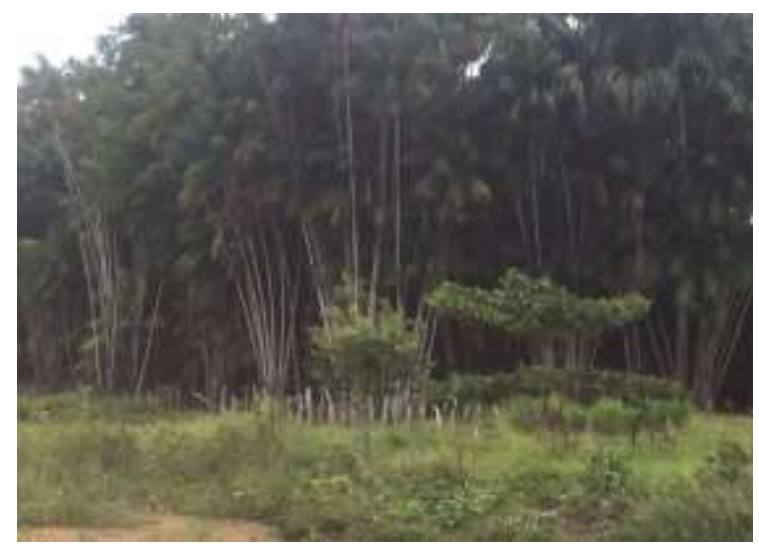

b)

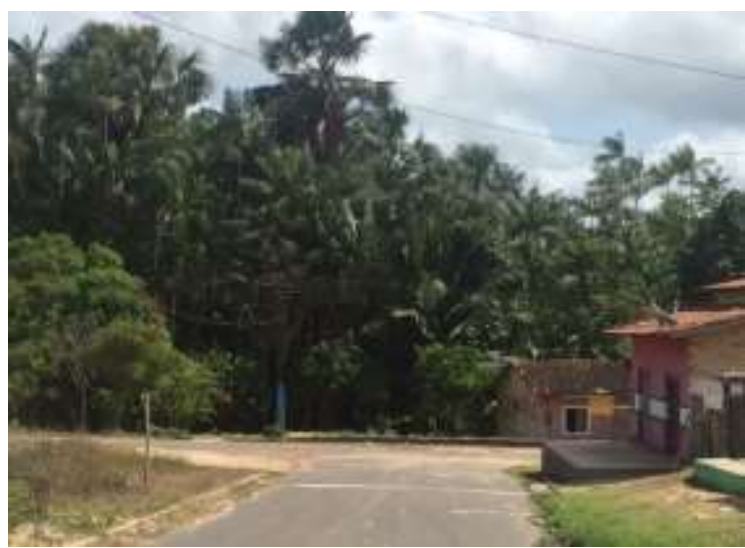

Fonte: Autores.

As matas de várzeas são caracterizadas pela oscilação das águas dos rios e das variações das marés, com a presença de diversas espécies de plantações típicas de áreas alagadas, como cupuaçu, os açaís e os buritis, utilizado pela população na coleta desses frutos, além de plantas medicinais, e extração de palhas e fibras (Fig. 3a). As áreas urbanas são próximas as áreas de mata (Fig. 3b). Já os campos de várzeas se caracterizam pela combinação de relevo de planície com a formação de gramíneas, e por isso, é muito utilizado para a criação de gados na região (Maranhão, 2001).

A terra firme corresponde ao ecossistema com maior diversidade e de extensão, visto que é influenciada pelas marés, sendo caracterizada pela zona da mata em diferentes estágios de regeneração. A principal cobertura vegetal são as capoeiras com palmeiras, com destaque para o babaçu, em que é coletado pela população (Maranhão, 2003).

\subsection{Metodologia do estudo}

O presente trabalho classifica-se como uma pesquisa epidemiológica retrospectiva descritiva do tipo documental, e trará como abordagem qualitativa e quantitativa. Onde, segundo Estrela, 2018, na pesquisa quantitativa são utilizadas técnicas 
estatísticas na tabulação dos dados, visando transformar as informações obtidas em números e, por seguinte em informações, para então serem analisadas, e na pesquisa qualitativa faz-se análise desses dados, ressaltando as particularidades do fato em estudo, e consequentemente emitindo assim sua opinião.

Quanto aos procedimentos metodológicos de coleta de dados, estes se deram a partir de buscas em documentos oficiais nas bases de dados do Programa Especial de Controle da Esquistossomose (PCE) e nas bases de dados da Fundação Nacional de Saúde (FUNASA) do município de Bacuri-Ma, dentro de um recorte temporal dos últimos dez anos (2011 a 2020). A população do Município de Bacuri foi considerada de acordo com o Censo do IBGE dos anos de 2010 e 2018. Para os demais anos, a população foi estimada de acordo com o crescimento demográfico observado entre os dois censos, adotandose uma taxa anual de aumento populacional de $1,5 \%$.

As localidades existentes no município são no total de 89, sendo que foram trabalhadas apenas uma média de 2 a 23 localidades, dentre elas os Sítios: Águas Belas, Bate pé, Batatal, Boca do Rio, Bom Jesus, Centro, Chapadeira, Fazenda, Pindobal, Ponta e São José e os seguintes povoados: Cabeceirinha, Varinta, Nazaré, Mutaca, Estiva e Barreira, totalizando uma população de 8.666 habitantes. É oportuno relatar, que essa totalidade de municípios trabalhados, se deu em decorrência das dificuldades vivenciadas pela FUNASA, no sentido de deficiência de contingente, além da dificuldade de acesso as localidades. Com exceção da sede do município, onde os munícipes procuram a FUNASA para estarem realizando o exame e tratamento para a esquistossomose, as demais localidades as buscas são realizadas de casa em casa, onde diante de suspeita da doença, os agentes visitam os domicílios, fornecendo potes para coletas de fezes, os potes são recolhidos no dia seguinte e encaminhados ao laboratório que fica na sede do município.

O método utilizado para análise das fezes é o proposto por Rabello em 1997, a técnica de Kato-Katz consiste na demonstração microscópica de ovos nas fezes e é recomendada pela Organização Mundial da Saúde (OMS). Essa técnica foi modificada do seu original por Katz et al, em 1972. Nem sempre são encontrados ovos na primeira amostra de fezes, na maioria das vezes é necessário realizar mais de uma coleta, onde a confirmação do diagnóstico pode se dar até na terceira amostra. Isto se dar, por conta da amostra de fezes coletada, não conter ovos, e diante dos sintomas apresentado pelo morador, o agente de saúde insiste na coleta de outras amostras. A análise das fezes é realizada no Laboratório de Parasitologia que fica na sede do município.

Após a coleta dos dados, eles foram organizados em tabelas e gráficos, para melhor explorar as informações obtidas. A análise estatística consistiu inicialmente em se avaliar a normalidade dos dados com teste Shapiro Wilk. Devido a carência de dados do ano de 2016, optou-se para comparar os resultados dos anos de 2011 a 2015 com os dos anos de 2017 a 2020 , procurando diferenças significativas entre os dados e tendências. Como a maior parte dos dados não apresentou distribuição normal foi utilizado o teste não paramétrico de Mann-Whitney. Complementando a análise de tendência, para cada variável foi utilizado modelo de regressão polinomial, sendo a variável independente os anos do levantamento. Todos os testes estatísticos foram realizados no software Statistica 7.0.

Atendendo à resolução nº 196/96 do Conselho Nacional de Saúde, que trata das normas para pesquisa envolvendo seres humanos, esta pesquisa foi aprovada pelo Comitê de Ética em Pesquisa da Universidade Ceuma - número do Parecer: 4.144.301 de 08 de julho de 2020. 


\section{Resultados}

\subsection{Dados gerais de 2011 a 2020}

Das 89 localidades existentes no Município de Bacuri, de 2 a 23 localidades foram trabalhadas no levantamento sobre a ocorrência e tratamento da esquistossomose entre os anos de 2011 e 2020. Essa pesquisa foi irregular ao longo dos anos, e não acompanhou o crescimento populacional (Fig.4a). Em média, por ano, foram atendidas 3.535 pessoas, tendo sido um menor atendimento observado em 2016 (37 pessoas) e um maior em 2014 (7.179 pessoas). Com isso, normalmente foi trabalhado um percentual de menos de $30 \%$ da população do município e, no ano com maior atendimento, este percentual atingiu apenas $42 \%$ (Fig. 4b).

O baixo percentual de atendimento se refletiu no número de localidades trabalhadas e consideradas positivas sobre as quais os dados foram levantados. Das 89 localidades existentes, no máximo 23 localidades foram atendidas, entre as quais, mais da metade até quase a totalidade registraram diagnósticos positivos (Fig. 5).

Figura 4: a) Densidade populacional anual do Município de Bacuri e população trabalhada na pesquisa sobre a presença de esquistossomose; b) Percentual da população do Município de Bacuri atendida pela pesquisa de esquistossomose.

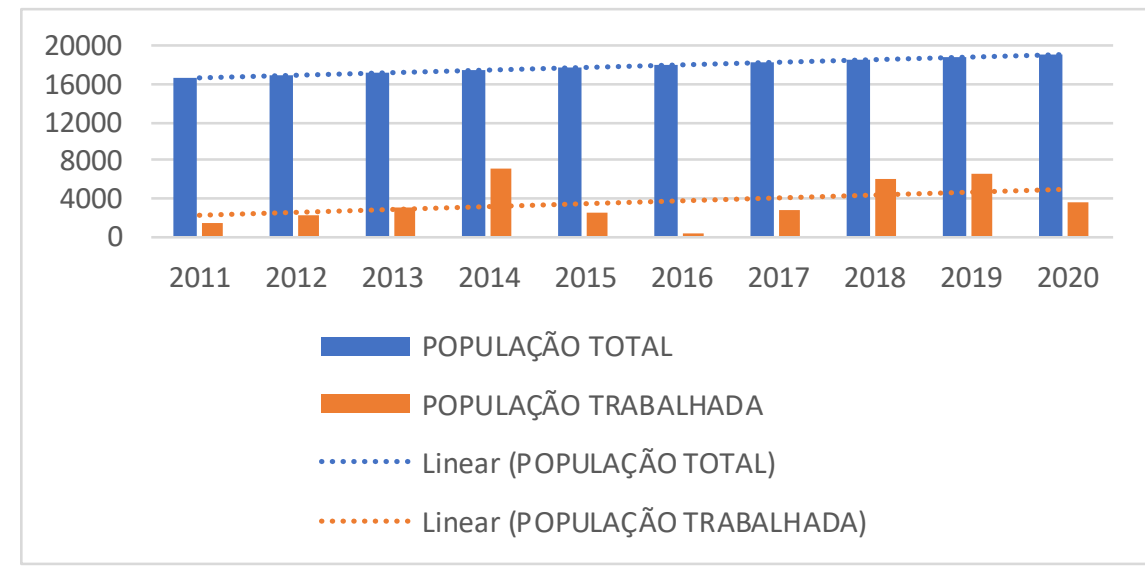

a)

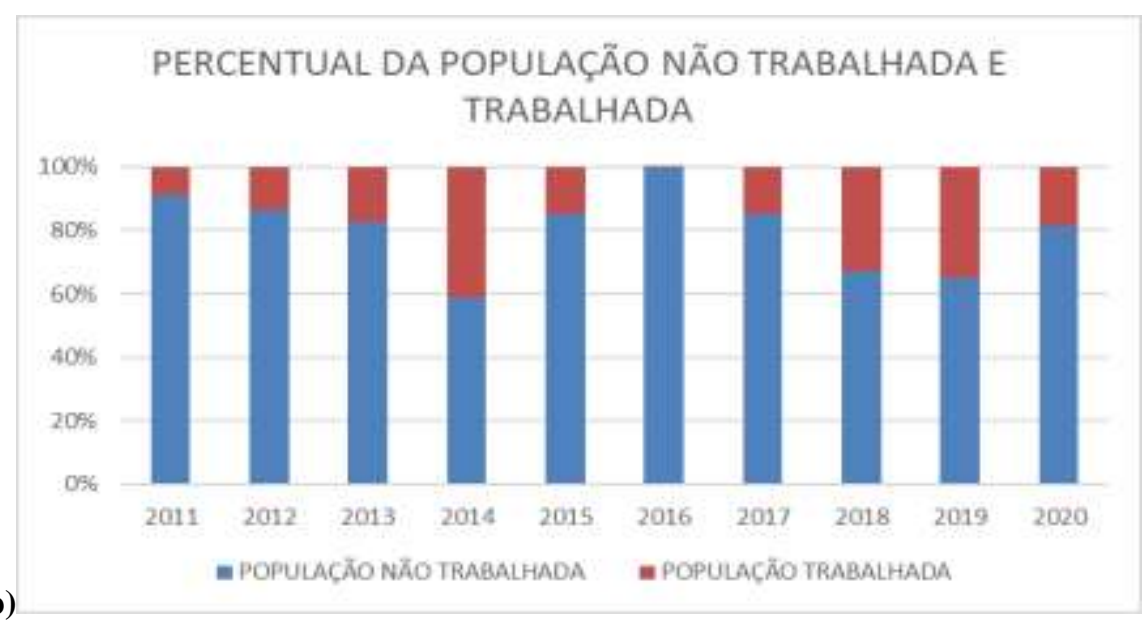

Fonte: Autores. 
Research, Society and Development, v. 10, n. 14, e129101421708, 2021

(CC BY 4.0) | ISSN 2525-3409 | DOI: http://dx.doi.org/10.33448/rsd-v10i14.21708

Figura 5: Número de localidades com diagnósticos positivos de 2011 a 2020.

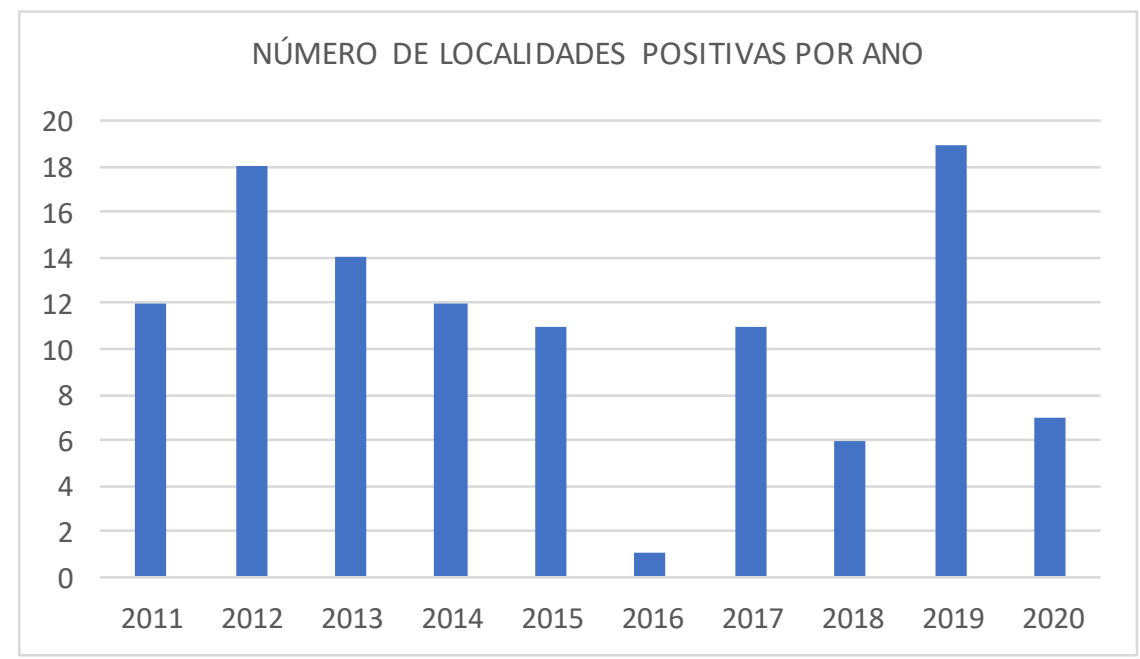

Fonte: Autores.

Entretanto, uma vez a localidade era trabalhada, os exames foram realizados em grande parte da população, ficando sem exames normalmente menos de $20 \%$ dos examinados (Fig.6a e b). Nos exames, realizados em média 3.216 por ano (Fig. 7a), a presença de ovos, correspondendo a casos positivos, ficaram entre 10 e 20\%, excetuando-se em 2016 quando houve um número reduzido de localidades estudadas e pessoas atendidas (Fig. 7b).

Figura 6: População trabalhada e exames realizados em termos totais (a) e em percentuais (b).

a)
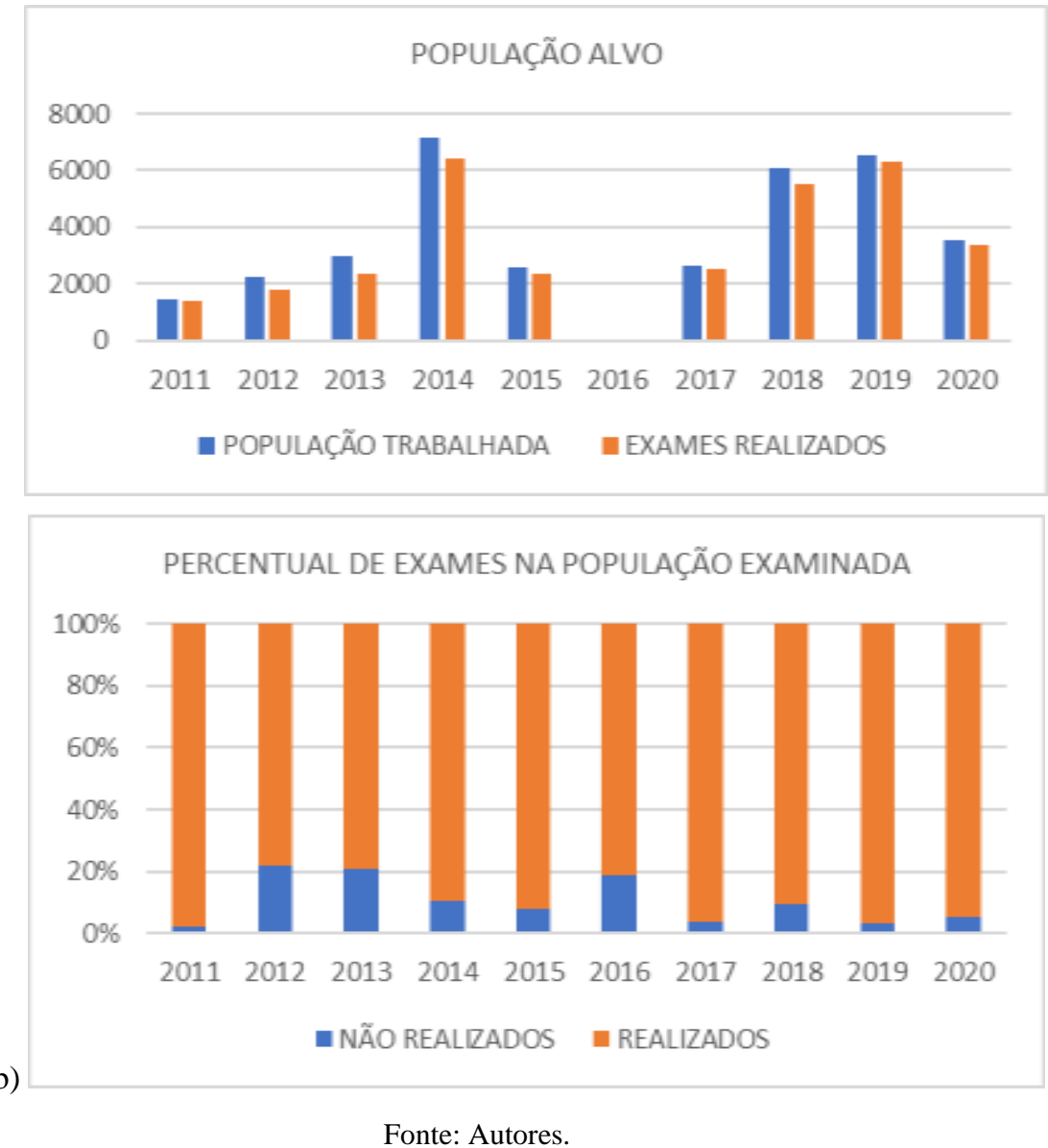
Research, Society and Development, v. 10, n. 14, e129101421708, 2021

(CC BY 4.0) | ISSN 2525-3409 | DOI: http://dx.doi.org/10.33448/rsd-v10i14.21708

Figura 7: Número de pessoas com ovos e sem ovos em termos totais (a) e em termos percentuais (b).

a)
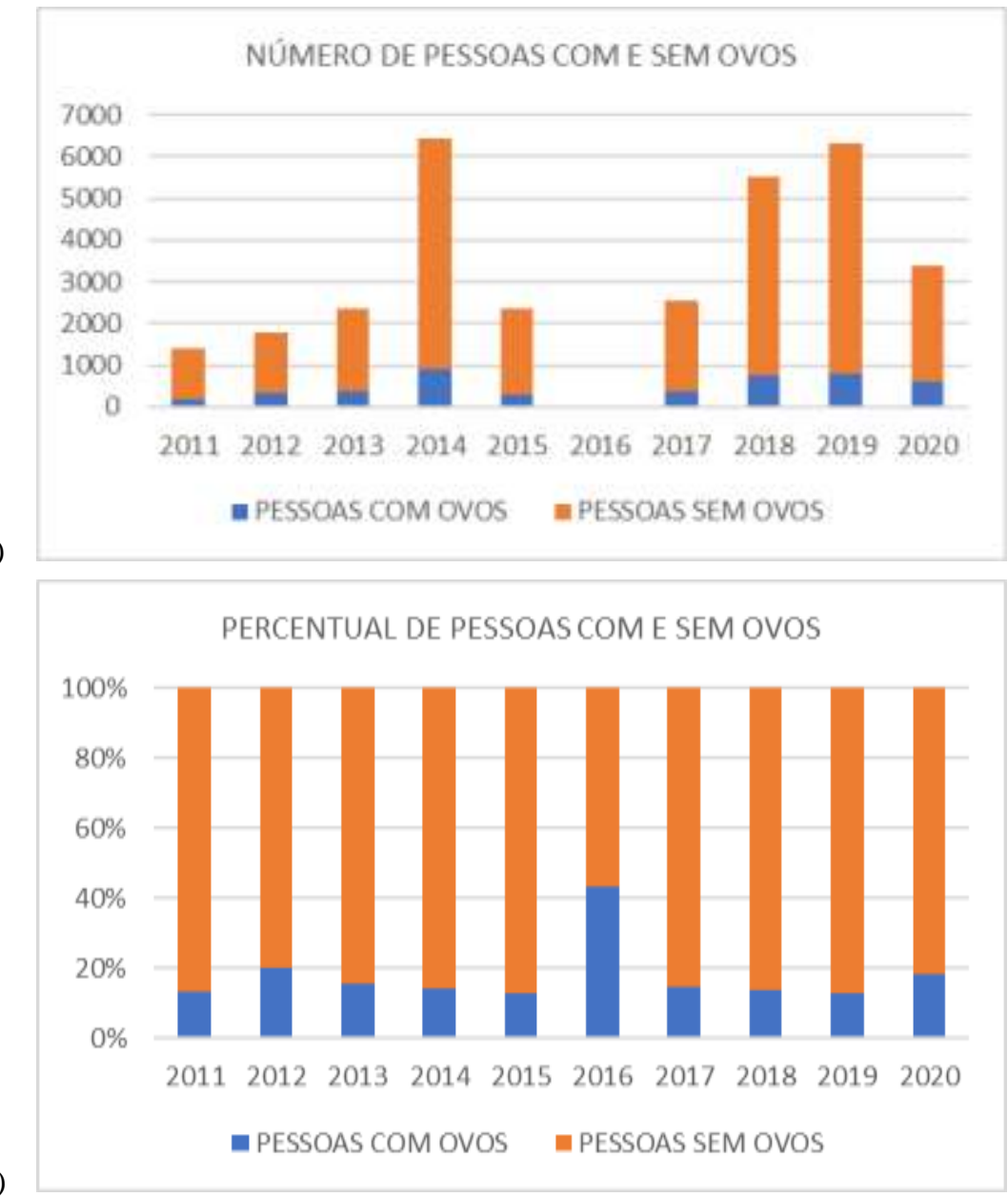

Fonte: Autores.

Na pesquisa de número de ovos de Schistosoma mansoni, o maior percentual foi referente à presença de 1-4 ovos por pessoa, seguido de 5-16 ovos, e um menor percentual de exames com mais de 17 ovos por pessoa (Fig. 8). Entre as verminoses diagnosticadas, a esquistossomose contribui em geral entre 40-50\% delas, excetuando-se 2016, o ano menos estudado, onde a esquistossomose foi responsável por 85\% dos diagnósticos de verminoses (Fig.9).

Figura 8: Percentual do número de ovos encontrados no exame de fezes para esquistossomose.

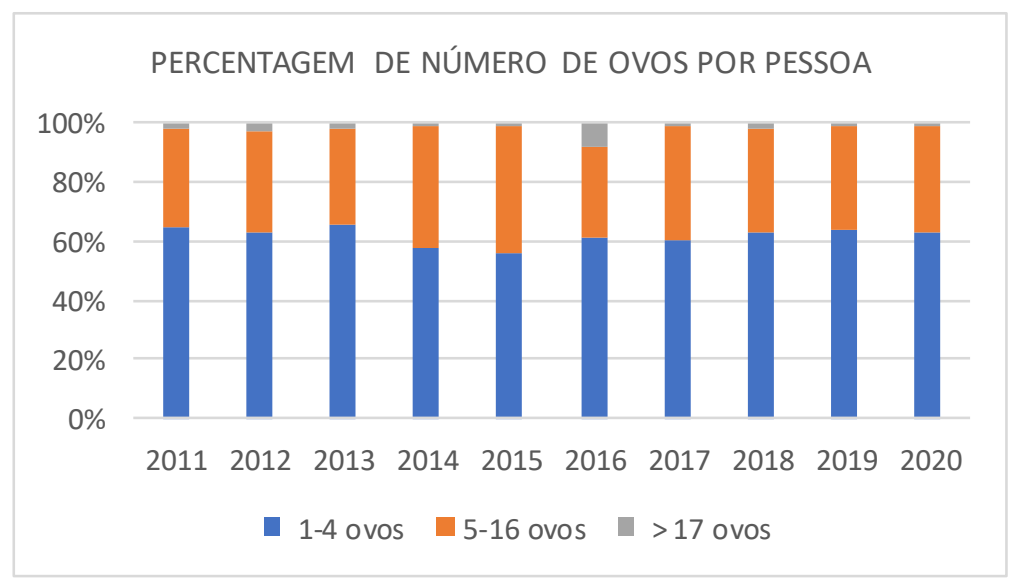

Fonte: Autores. 
Research, Society and Development, v. 10, n. 14, e129101421708, 2021

(CC BY 4.0) | ISSN 2525-3409 | DOI: http://dx.doi.org/10.33448/rsd-v10i14.21708

Figura 9: Percentual da esquistossomose em relação a outras verminoses encontradas.

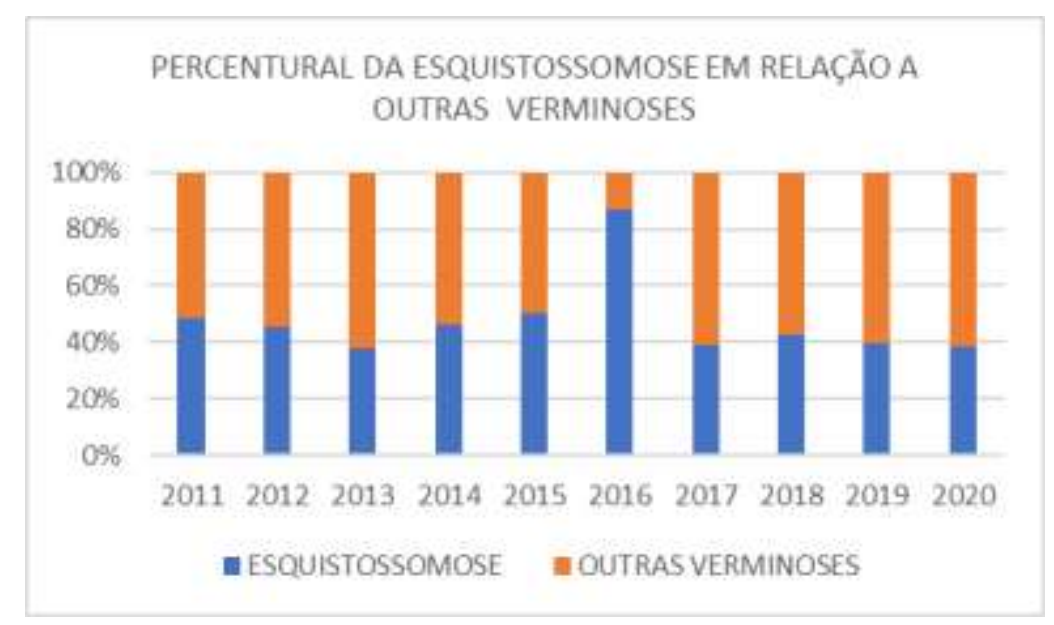

Fonte: Autores.

Quanto a questão do tratamento, até 2016, a maior parte das pessoas diagnosticadas foram tratadas, entretanto, a partir de 2017 o número de pessoas não tratadas vem aumentando (Fig.10a). As causas do não tratamento variam entre não indicado, recusa e ausência do paciente (Fig. 10b).

Figura 10: a) Número de pessoas com esquistossomose, pessoas tratadas e não tratadas; b) número de pessoas não tratadas com a causa do não tratamento.

a)

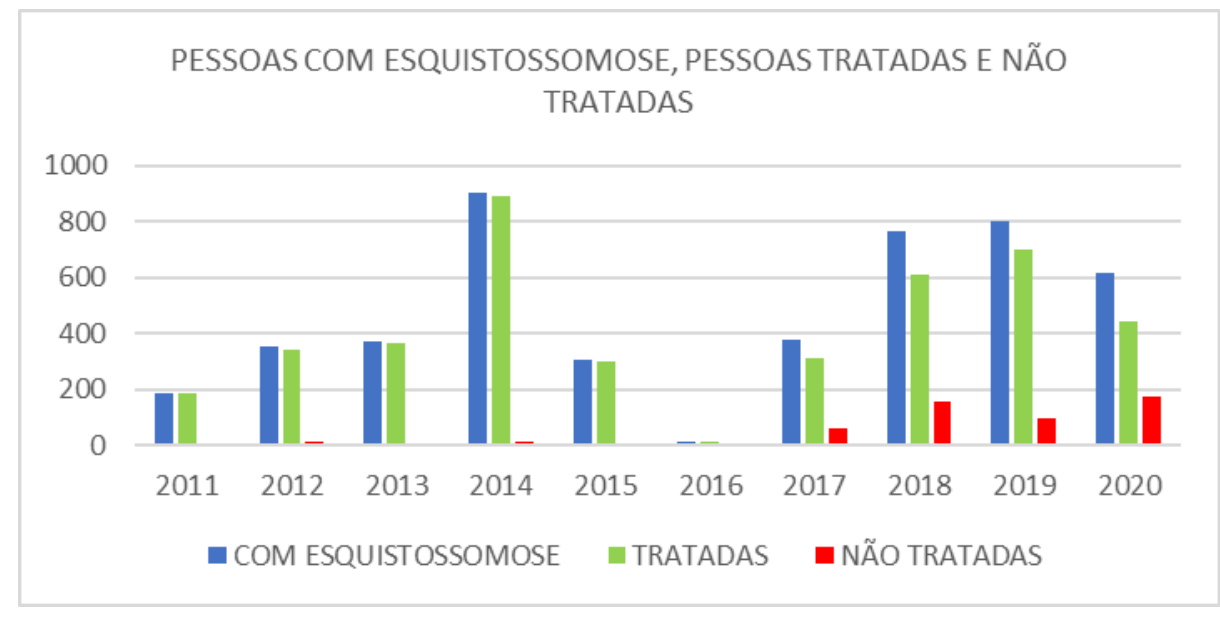

b)

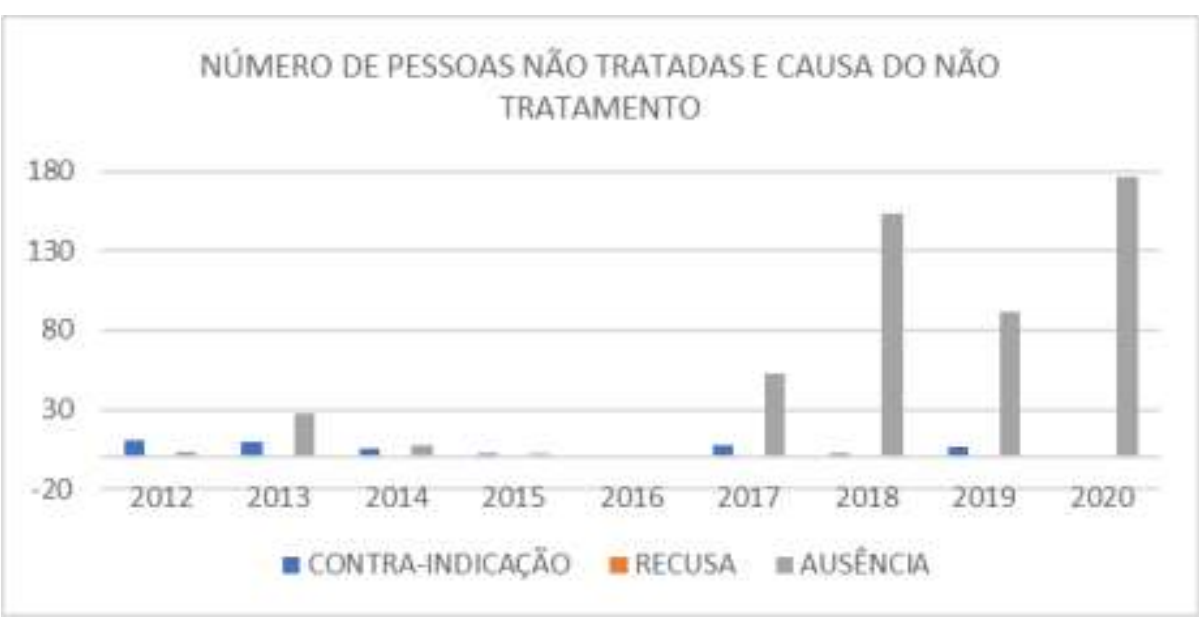

Fonte: Autores. 


\subsection{Comparação entre os períodos de 2011-2015 e de 2017-2020 e análise de tendência}

Apesar de aparentemente ter havido um aumento das populações trabalhadas e do número de pessoas com esquistossomose diagnosticadas entre os períodos analisados, estas diferenças não foram estatisticamente significativas de acordo com o teste de Mann-Whitney. No entanto, foram considerados significativamente diferentes os resultados referentes a proporção de localidades positivas, pessoas a tratar e pessoas não tratadas por ausência entre os dois grupos de anos (Zadj=$2,449 ; \mathrm{p}=0,014)$. A proporção de localidades positivas aumentou, com a mediana nos primeiros anos abaixo de $20 \%$ e nos últimos acima de $80 \%$ (Fig.11a). Já as pessoas a tratar a mediana foi de 10 para 110 (Fig. 11b) e a mediana das pessoas não tratadas por ausência teve um aumento também expressivo (Fig. 11c).

Figura 11: Comparação o percentual de localidades positivas (a), pessoas a tratar (b) e não tratadas por ausência (c) entre os anos de 2011-2015 e 2017-2020.

a)

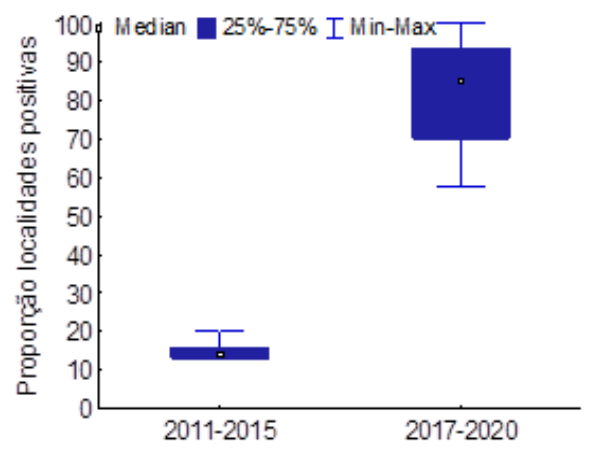

b)

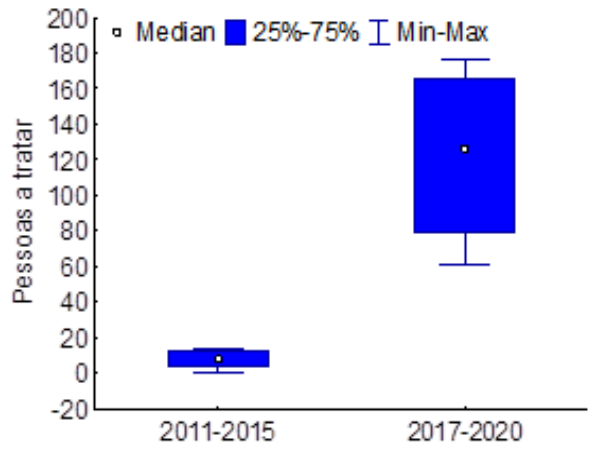

c)

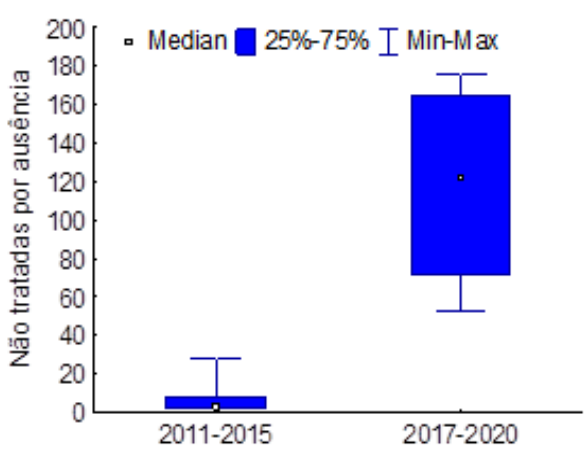

Fonte: Autores.

A análise de regressão, confirmou a tendência de aumento temporal para o percentual de localidades positivas $(\mathrm{F}(1,8)=31,87 ; \mathrm{p}=0.00048 ; \mathrm{R} 2 \mathrm{aj}=0.774)$, aumento do número de pessoas a tratar $(\mathrm{F}(1,8)=17,65 ; \mathrm{p}=0.00299 ; \mathrm{R} 2 \mathrm{aj}=0.649)$ e aumento do número de pessoas não tratadas ao longo dos anos $(F(1,8)=15,82 ; \mathrm{p}=0.0041 ; \mathrm{R} 2 \mathrm{aj}=0.622)$.

\section{Discussão}

O presente estudo teve corroborada a sua hipótese inicial de que o município de Bacuri é uma área endêmica para a esquistossomose, tendo sido em todos os anos do recorte temporal avaliado (2011-2020) encontradas localidades com diagnósticos positivos para esta parasitose. A localização na Baixada Ocidental Maranhense, caracterizada por áreas com cobertura por vegetação alagada favoráveis a reprodução de caramujos transmissores (Lira et al., 2017), as atividades da população ligadas ao extrativismo vegetal, pesca artesanal, portanto com contado frequente com os sistemas aquáticos (Mendes et al., 2017) e falta de saneamento propicia a endemicidade esperada. 
Entretanto, a segunda hipótese de que a maioria das localidades apresenta casos positivos de esquistossomose não pode ser corroborada já que não foi investigada a maior parte das localidades do Município de Bacuri. Entre as 89 localidades existentes neste município, apenas de 2 a 23 foram trabalhadas no levantamento sobre a ocorrência e tratamento da esquistossomose, apontando o levantamento epidemiológico como irregular ao longo dos anos, e não acompanhando o crescimento populacional. Com isso, normalmente foi trabalhado um percentual de menos de $30 \%$ da população do município e, nos anos com maior atendimento (2012 e 2019), este percentual atingiu no máximo 42\%. No entanto, esse percentual não é muito diferente de outros, já que Mendes et al (2017), analisando a pesquisa de esquistossomose em municípios endêmicos para esta parasitose no Estado do Maranhão, reportaram percentuais de pessoas pesquisadas entre 10 e $48 \%$ da população dos municípios investigados.

Contudo, vale ressaltar o resultado efetivo prático do presente estudo, mostrando que uma vez trabalhada a localidade, os exames para a pesquisa do $S$. mansoni foram realizados em grande parte da população em questão. Considerando todas as localidades trabalhadas por ano, foi observada a prevalência de uma alta ocorrência de esquistossomose, já que o percentual de registro de diagnóstico positivo para esquistossomose ficou entre 12,6 e 43,3\%. Este último percentual, foi referente ao ano de 2016 no qual apenas uma localidade foi pesquisada e mostra como uma única localidade pode apresentar uma alta incidência de esquistossomose. Com isso, a média do percentual de casos positivos ficou em 17,8\%. Este valor foi superior ao encontrado na maioria dos municípios do Estado do Maranhão e em outros estados do Nordeste. Um valor máximo de 15,2\% foi encontrado por Silva; Brito et al., (2020) em estudo sobre a situação epidemiológica e controle da esquistossomose no Estado de Pernambuco de 2010 a 2016. Já Dos Santos et al., (2016) analisando esta parasitose no Município de Simão Dias, no Estado de Sergipe, encontrou prevalência de $16,1 \%$ de casos positivos em uma localidade estudada.

A cidade de Palmeirândia (MA), também é um município localizado na Baixada Ocidental Maranhense e que também aparece com indicadores relevantes da parasitose apresentou menor incidência para esquistossomose (entre 1,8 e 2,5\%), apesar de que a zona rural apresenta condições ecológicas favoráveis à transmissão e expansão da doença (Pinheiro et al., 2020). Em um estudo temporal realizado por Mendes (2019) no período entre 2007 e 2016 na região a qual pertence o município de Palmeirândia, observou-se uma taxa de 3,1\% de prevalência, mostrando-se estável.

Para o município de Tutoia, localizado na Baixada Litorânea Oriental do Estado do Maranhão (MA), há o registro de um percentual de prevalência de 3,2\% de casos positivos para 2008 (Santos; Mello, 2011). Vale enfatizar que o percentual da população avaliada no presente estudo foi menos de $30 \%$ de todos os habitantes do munícipio diferentemente, da população estudada em Tutoia que foi $78 \%$ da população.

Estudando a prevalência da esquistossomose no Estado do Maranhão de 1997 a 2003, Cantanhede et al., (2011) verificaram municípios com tendência de queda constante ao longo da série histórica (Bacabal e São Luís), alguns com aumento da prevalência até 2002 (Colinas), seguido de tendência de queda e outros com uma tendência ascendente constante (Imperatriz); observam que a tendência de declínio da prevalência da esquistossomose torna-se duvidosa, uma vez que pode haver subnotificações na região. Estes mesmos autores reportam as maiores incidências para os municípios de Bacabal $(12,8 \%)$ e Presidente Dutra (9\%), e o aumento da prevalência relacionado a questões socioeconômicas destes municípios, uma vez que há déficit de saneamento básico, com altos índices de pobreza e a eventos de imigração populacional. Mendes et al., (2017) avaliando a pesquisa da esquistossomose de 2005 a 2015 em municípios considerados endêmicos no Maranhão, associaram a maior prevalência de casos com municípios com os menores Índices de Desenvolvimento Humano Municipal (IDHM), e concluíram que, embora o Maranhão tenha vários municípios endêmicos e locais com risco de infecção pela esquistossomose mansoni, a cobertura de pesquisa para essa parasitose ainda é baixa. Como consequência, segundos estes mesmos autores, a queda no número de casos positivos reflete uma menor cobertura de pesquisas nos municípios e não um controle efetivo da esquistossomose. 
Pode-se então ser observado que no Estado do Maranhão existem municípios com baixa endemicidade para a esquistossomose mansoni, e outros com alta prevalência para a doença, como é o caso dos localizados na Baixada Ocidental Maranhense (Lira et al., 2017). Segundo Lira et al., (2017) e Mendes et al., (2017) essa região é altamente prevalente para esquistossomose devido a presença de áreas alagadas, sendo pontos favoráveis a reprodução dos moluscos transmissores da doença e as inúmeras atividades humanas em contato com a água.

É enfatizado pelo presente estudo, que a esquistossomose no Município de Bacuri se destaca entre as verminoses registradas na população, sendo a mais diagnosticada nas 23 localidades trabalhadas no período entre 2011 e 2020. A esquistossomose chega a ser de 38 a $86 \%$ das verminoses diagnosticadas. Estudos mais aprofundados relativos as demais verminoses podem vir a ser interessantes, já que recentemente tem sido evidenciado que infecções concomitantes por $S$. mansoni e algumas espécies de vermes nematódeos em humanos resultam em um padrão de esquistossomose que difere das infecções isoladas, sugerindo uma relação sinérgica ou antagonista entre os parasitas.

Sob outro aspecto, de acordo com os resultados do presente estudo, a proporção de localidades positivas aumentou ao longo do tempo, juntamente com o número de pessoas a tratar. A maior parte das pessoas diagnosticadas foram tratadas, entretanto a partir de 2017 a proporção de localidades positivas vem aumentando, o que causa preocupação devido à alta proporção de pessoas positivas.

Embora não se tenham sido levantados dados mais detalhados sobre a intensidade de infecção, como o cálculo do número de ovos por grama de fezes, o maior percentual encontrado de pessoas com 1-4 ovos sugere uma infecção leve na maior parte da população. Entretanto, a presença em todos os anos de pessoas com uma certa quantidade de ovos, sugere a presença significativa de indivíduos portadores do parasito, que correm risco de desenvolver as formas graves e debilitantes da doença, as quais podem estar a associadas à intensidade da infecção (Dos Santos et al., 2016).

O diagnóstico é essencial para as intervenções, como no caso de Bacuri, mesmo diante da dificuldade em recurso humano para realizar os exames. Na estratégia empregada, o agente de saúde fornece um frasco para coleta da amostra de fezes para o indivíduo com sintomas, e recolhe no dia seguinte; a amostra é analisada no mesmo dia, mas nem sempre é detectado presença de ovos nessa amostra, sendo necessário nova coleta até apresentar positividade, as vezes se detecta na terceira amostra.

Deve ser salientado, no entanto, que no munícipio de Bacuri um fator que provavelmente tem contribuído para a elevada incidência de casos de esquistossomose mansônica é a falta de tratamento dos casos positivos, como foi possível observar no presente estudo. Verificou-se um aumento temporal expressivo do número de pessoas não tratadas, especialmente pela ausência, embora possa também haver não indicação ou recusa.

Ressalta-se a importância do tratamento em comunidades com elevado número de casos positivos. De acordo com as Diretrizes técnicas da Vigilância da Esquistossomose mansoni do Ministério da Saúde (Brasil, 2014), na estratégia de tratamento para portadores de S. mansoni, com um percentual de positividade entre 15 e $25 \%$, como no caso da maior parte das localidades do Município de Bacuri, devem ser tratados os indivíduos com exame parasitológico de fezes positivo e os conviventes.

Em Bacuri, o tratamento da infecção por esquistossomose é feito com o praziquantel, que é o medicamento indicado pelo Ministério da Saúde. Este medicamento é administrado em dose única, no entanto há relatos de recusa do tratamento devido fatores adversos, desde o sabor do medicamento a efeitos colaterais. Contudo, deve também ser ressaltado a ineficácia do praziquantel como estratégia isolada para eliminação da esquistossomose em regiões hiperendêmicas (Brito; Silva; Quinino, 2020).

O tratamento dos casos positivos é fundamental para interromper o ciclo de transmissão da doença, sendo o fornecimento do tratamento uma das principais estratégias para alcançar a redução na positividade (Nascimento et al., 2020) e 
faz parte do Programa Especial de Controle da Esquistossomose (PECE). Segundo Cantanhede et al., (2011) com a descentralização do programa no período de 1999-2003, as ações de controle passaram a ser de responsabilidade dos municípios. Porém, as secretarias municipais de saúde têm tido dificuldade em manter esse controle, o que pode mascarar os dados reais da doença na localidade. Como visto em outros estados do nordeste, a diminuição no percentual de pessoas tratadas pode estar relacionada a carência de agentes de saúde nas atividades de rotina do PECE, resultando em decréscimo de diagnósticos e no tratamento das pessoas infectadas (Soares et al., 2019).

Embora inexistam dados em literatura sobre os moluscos transmissores presentes no Município de Bacuri, como em outros locais do Estado do Maranhão, torna-se importante pesquisas sobre estes hospedeiros intermediários. Com relação ao município de Tutóia, foram encontradas grandes quantidades de moluscos infectados pelo parasita $S$. mansoni da espécie $B$. glabrata no rio que banha a região (Santos; Melo, 2011). A ocorrência maior da esquistossomose no Brasil nos estados das Regiões Nordeste e Sudeste tem sido diretamente ligada à presença dos moluscos transmissores (Brasil, 2018; Lima et al., 2021), apesar de alguns municípios ter registro como contaminação exógena, principalmente em decorrência da imigração ou turismo rural (Santana et al., 2014).

Estes dados reforçam a necessidade de investigação maciça em diversas regiões do estado, facilitando a identificação de focos de infecção dos parasitas e posterior intervenções no local, tornando não efetivo apenas intervenções a nível quimioterápico (Santos; Melo, 2011; Teles, 2005). O município de São Bento, no interior da Baixada Maranhense apresentando de $5 \%$ a $14 \%$ de casos positivos, é considerado em uma área de média endemicidade. No entanto, criadouros investigados neste município foram negativos para $S$. mansoni, sendo nesse caso o ideal enquadrá-los como potencialmente de risco para a transmissão de esquistossomose mansônica (Nogueira et al., 2016).

Além dos moluscos transmissores, estudos também tem relatado a participação de um roedor silvestre (Holochilus sciureus) com hábito de vida semiaquático na epidemiologia da esquistossomose. A pesquisa com esse roedor no Município de São Bento (MA), mostrou que entre 225 animais, 144 (64\%) exibiram ovos de Schistosoma em suas amostras de fezes podendo então desempenhar um papel como reservatório de $S$. mansoni nesta região, uma vez que foi encontrado naturalmente infectado (Silva-Souza et al., 2019).

Apesar da importância de ações no controle desses hospedeiros intermediários da esquistossomose nos estados do Nordeste do Brasil (Nascimento et al., 2020), as maiores dificuldades estão relacionadas às más condições sanitárias do Municípios. Em Bacuri, as localidades urbanas e rurais não contam com rede coletora de esgoto doméstico, o que torna essa problemática acentuada. Realidade vivenciada, nos outros municípios do Estado do Maranhão (Santos et al., 2011; Mendes et al., 2017) e de outros estados do Nordeste do país (Brasil, 2018). Mesmo diante das evidências de que ações referentes às regionais do Maranhão terem sido afetados pela descentralização do PECE (Cantanhede et al., 2011), e apesar da importância do tratamento farmacológico, é notório que há necessidade de intervenções em nível do meio ambiente circundante às populações e de saneamento básico para o controle efetivo.

Considera-se que os índices elevados se devem a exposição da população aos fatores de riscos predisponente da esquistossomose (Cantanhede et al., 2014). Apesar da maior prevalência estar relacionada à área rural por estas serem onde se encontra a maior parte de populações vivendo em condições inadequadas de saneamento básico, a esquistossomose também tem incidência em área urbana. Portanto, trata-se de uma doença, relacionada a aspectos socioeconômicos e ambientais e, dessa forma, qualquer localidade com deficiência de saneamento está sobre risco de haver incidência de esquistossomose (Guedes; Cunha, 2012).

É peculiar a situação ocorrida no Maranhão, considerando que a disseminação e transmissão da esquistossomose se dar por falta de saneamento básico. Na Baixada Maranhense é comum a presença de irregularidades no abastecimento d'água, sendo que grande parte das residências da baixada maranhense tiram a água para seu uso diário de poços e cacimbas, além do 
mais, a coleta de lixo muitas vezes não é realizada ou é feita de forma irregular, contribuindo para essa problemática. Outro fator é a desigualdade social, com aumento do desemprego, o qual contribui com um número maior de pessoas vivendo em condições precárias, fatores que também contribuem com o aumento da disseminação da esquistossomose (Ramos; da Silva; Silva, 2007). Em Bacuri, as atividades da população relacionadas ao extrativismo vegetal (babaçu, buriti e a juçara), agricultura de subsistência, e a pesca artesanal, acentuam o contato de trabalhadores com os sistemas aquáticos (habitat natural dos moluscos transmissores).

Fazendo uma comparação com outros estado brasileiros, vale enfatizar que os maiores índices de prevalência da esquistossomose na população são vistos nos estados de Pernambuco, Sergipe e Alagoas na Região Nordeste sendo que em Sergipe a média no período de 2005 a 2010 foi de 9,2\%, um índice acima da média nacional 5,9\%. No caso do estado do Maranhão a incidência possui distribuição focal, isto é, existem algumas áreas que apresentam fatores para o desenvolvimento e reprodução do transmissor (Barreto, 2015; Mendes et al., 2017) o que justifica as diversas variações de taxa de prevalência em diversos munícipios do estado.

Apesar de ter sido evidenciada uma queda no número de casos positivos de esquistossomose entre 2010 e 2017 na região Nordeste, acentuando-se esta redução a partir de 2015 (Nascimento et al., 2020) e historicamente também no país, destaca-se que o indicador de percentual de positividade não reflete necessariamente a prevalência, já que não utiliza a totalidade da população sob risco ou uma parcela representativa desta (Brasil, 2014). Isto pode ser ressaltado no presente estudo, onde o resultado geral indicou dados de um percentual restrito da população do município estudado e, diferentemente do cenário de queda de números de casos, mostrou um aumento nas localidades com casos positivos.

Deve ser salientado também que, ao conjunto que envolve a carência de agentes de saúde para a pesquisa e tratamento da esquistossomose, a presença de criadouros naturais para hospedeiros intermediários e o contato frequente e natural das populações humanas com áreas aquáticas de risco, se soma a carência de levantamentos e pesquisas mais aprofundadas sobre esta parasitose no Estado do Maranhão. Em um levantamento recente sobre a produção científica e tecnológica sobre a esquistossomose no Estado do Maranhão, Lima et al., (2021) verificaram que apesar dessa parasitose constituir um problema de saúde pública no estado desde 1920, apenas 21 artigos foram encontrados, a maioria sobre a epidemiologia da doença (38\%) e aplicação de extratos contra os caramujos transmissores (31\%), entre outros.

\section{Considerações Finais}

Esperamos que os resultados do presente estudo, que demonstrou a situação epidemiológica da esquistossomose em um recorte de tempo no Município de Bacuri venham contribuir para a melhoria da gestão da pesquisa e tratamento desta parasitose nas localidades desse município. O município estudado, como vários do estado do Maranhão, apresentou alta prevalência e incidência para esquistossomose, já que diante de uma média de $30 \%$ da população avaliada, obteve-se uma incidência média de 17,8\% de positividade. Ressalta-se mais uma vez a endemicidade da esquistossomose em um município da Baixada Ocidental Maranhense. Tal fato está relacionado a situação socioeconômica, ambiental e de saneamento básico de municípios desta região.

Destacam-se as condições de grande parte da população, que vive em condições sub-humanas, exposta a situação precária de moradias, sem acesso a água potável e a rede de esgoto. No entanto, salienta-se que a esquistossomose não se constituiu doença predominantemente rural, já que a proximidade dos núcleos urbanos de área com vegetação natural e o contato constante de seus moradores com áreas alagadas naturais, seja por questão de trabalho (extrativismo, pesca artesanal) ou de lazer (banho, pesca recreativa) os expõe a áreas de risco, potencialmente com presença de cercarias do $S$. mansoni.

No entanto, sob outro aspecto, por se tratar de uma doença de característica assintomática nas fases iniciais podendo se agravar nas fases tardias, e o diagnostico muitas vezes não é confirmado, há na maioria das vezes subnotificação dos casos. 
Esse cenário contribuiu também para um ofuscamento do problema e, nesse sentido, muitas vezes ações de combate a esse parasita não são desenvolvidas, até mesmo devido a presunção de pouca ocorrência de casos. Apesar disso, o aumento da proporção de localidades com casos positivos, o aumento do número de pessoas a tratar e, em especial, o aumento de pessoas não tratadas por ausência, como o diagnosticado pelo presente estudo ressaltam a importância da ação do agente de saúde e a questão educacional da população quanto a importância da prevenção e do tratamento da esquistossomose.

Reforça-se ainda a necessidade de investimentos e incentivo a pesquisa científica visando intervenções não somente farmacológicas, mas também em nível prevenção, destaque da importância do tratamento e cuidado com o meio ambiente. Salienta-se, como urgente e premente, um esclarecimento maior à população no que diz respeito a problemática da esquistossomose. Na maioria das vezes, a população não é conhecedora das formas de contágio, diagnóstico e tratamento desta doença, que são coadjuvantes fundamentais no processo de combate e controle da esquistossomose. Por outro lado, também se ressalta a necessidade de esclarecimento à população, aos dirigentes e aos tomadores de decisão da importância inestimável e inegociável de ações de saneamento a nível urbano e rural para controle da esquistossomose e demais doenças de veiculação hídrica.

Diante do fato dessa parasitose constituir um problema de saúde pública, e da pouca quantidade de estudos anteriores, é reiterada a necessidade de pesquisas aprofundadas acerca da esquistossomose no estado do Maranhão como um todo, onde se percebe condições históricas de endemicidade em paralelo com escassez de publicações trazendo à tona a problemática aqui evidenciada. Ressalta-se a necessidade de um amplo estudo epidemiológico no estado do Maranhão e mais incentivos e investimentos para pesquisas relacionadas à esquistossomose, despertar a mentalidade científica nos sistemas educacionais e na sociedade em geral, e mais recursos para equipar laboratórios e as universidades que venha subsidiar pesquisas sobre a parasitose.

\section{Agradecimentos}

C.L.L. agradece o apoio CAPES, através da bolsa de doutoramento. Agradece também a FUNASA do Município de Bacurí-MA na pessoa do atual coordenador Luís Rodrigues de Souza.

\section{Referências}

Bacuri, P. M. (2020). Secretaria Municipal de Planejamento e Coordenação Geral. Histórico de Bacuri. https://www.bacuri.ma.gov.br/cidades/cidades/

Barreto, A. V. M. S., Melo, N. D., Ventura, J. V. T., Santiago R. T., \& Silva, M. B. A. (2015). Análise da positividade da esquistossomose mansoni em Regionais de Saúde endêmicas em Pernambuco, 2005 a 2010. Epidemiologia e Serviços de Saúde, v. 24, p. 87-96.

Brasil. (2018). Ministério da Saúde. Secretaria de Vigilância em Saúde. Departamento de Vigilância das Doenças Transmissíveis. Educação em saúde para o controle da esquistossomose / Ministério da Saúde, Secretaria de Vigilância em Saúde, Departamento de Vigilância das Doenças Transmissíveis. - Brasília: Ministério da Saúde, 40 p.: il. ISBN 978-85-334-2676-4. https://bvsms.saude.gov.br/bvs/publicacoes/educacao_saude_controle_esquistossomose.pdf.

Brasil. (2021). Ministério da Saúde. Doenças tropicais negligenciadas 30 de janeiro - Dia mundial de combate às Doenças tropicais negligenciadas. Secretaria de Vigilância em Saúde (SVS). Boletim epidemiológico. Ministério da Saúde Número Especial. https://www.gov.br/saude/ptbr/media/pdf/2021/marco/3/boletim_especial_doencas_negligenciadas.pdf

Brasil. (2014). Ministério da Saúde. Secretaria de Vigilância em Saúde. Departamento de Vigilância das Doenças Transmissíveis. Coordenação-Geral de Hanseníase e Doenças em Eliminação. ( $4^{\circ}$ ed.) - Brasília: Ministério da Saúde.

Brasil. (2014). Ministério da Saúde. Secretaria de Vigilância em Saúde. Departamento de Vigilância Epidemiológica. Vigilância da Esquistossomose Mansoni: diretrizes técnicas / Ministério da Saúde, Secretaria de Vigilância em Saúde, Departamento de Vigilância das Doenças Transmissíveis. (4º ed.) Brasília: Ministério da Saúde.

Brito, M. I. B. da S., Silva, M. B. A., \& Quinino, L. R. de M. (2020). Situação epidemiológica e controle da esquistossomose em Pernambuco: estudo descritivo, 2010-2016. Epidemiologia e Serviços de Saúde, p29. https://doi.org/10.5123/S1679-49742020000200015

Cantanhede, S. P. D., Fernandez, M. A., Mattos, A. C. de., Montresor, L. C., Silva-Souza, N., \& Thiengo, S. C. (2014). Freshwater gastropods of the Baixada Maranhense Microregion, an endemic area for schistosomiasis in the State of Maranhão, Brazil: I-qualitative study. Revista da Sociedade Brasileira de Medicina Tropical, 47:79-85. https://doi.org/10.1590/0037-8682-0194-2013 
Cantanhede, S. P. D. (2015). Gastrópodes límnicos e helmintofauna associada da Microrregião da Baixada Maranhense, MA, com ênfase nos transmissores da esquistossomose. 2015. 211f. Tese (Doutorado em Biodiversidade e Saúde) - Fundação Oswaldo Cruz, Instituto Oswaldo Cruz, Rio de janeiro, RJ.

Cantanhede, S. P. D., Ferreira, A. P., \& Mattos, I. E. (2011). Esquistossomose mansônica no Estado do Maranhão, Brasil, 1997-2003. Cadernos de Saúde Pública, 27:811-816. https://doi.org/10.1590/S0102-311X2011000400020

Cantanhede, S. P. D., Fernandez, M. A., Mattos, A. C. de., Montresor L. C., Silva-Souza, N., \& Thiengo, S. C. (2014). Freshwater gastropods of the Baixada Maranhense Microregion, an endemic area for schistosomiasis in the State of Maranhão, Brazil: I-qualitative study. Revista da Sociedade Brasileira de Medicina Tropical, v. 47, p. 79-85.

Cardoso, M. F. (2011). O Maranhão por dentro. São Luís: LITHOGRAF. 610 p.

Carvalho, I. B. de. (2014). Avaliação do Programa de vigilância e controle da esquistossomose no município de São Luis, Ma. 2014. 121 f. Dissertação (Mestrado em Saúde e Meio Ambiente) - Universidade Federal do Maranhão, São Luís.

Cruz, J. I. N., Salazar, de O. G., \& La Corte, R. (2020). Retrocesso do Programa de Controle da Esquistossomose no estado de maior prevalência da doença no Brasil. Revista Pan-Amazônica de Saúde, 11:9-9. http://dx.doi.org/10.5123/s2176-622320200056

dos Santos, A. D., Santos, M. B., dos Santos, P. G. R., Barreto, A. S., \& Araújo, K. C. G. M. (2016). Análise espacial e características epidemiológicas dos casos de esquistossomose mansônica no município de Simão Dias, nordeste do Brasil. Revista de Patologia Tropical/Journal of Tropical Pathology, 45(1):99114. https://doi.org/10.5216/rpt.v45i1.39978

Estrela, C. (2018). Metodologia Científica: Ciência, Ensino, Pesquisa. Editora Artes Médicas.

Frantini, J. R. G., Saupe, R., \& Massaroli, A. (jan/março 2008). Referência e contras referência: contribuição para a integralidade em saúde. Ciência Cuidado Saúde, 065-072. https://pesquisa.bvsalud.org/portal/resource/pt/lil-647374

Guedes, S. A. G., \& Cunha, L. D. A. (2012). Prevalência de esquistossomose mansônica na cidade de Nossa Senhora do Socorro, Sergipe, 2001-2006. Ideias e Inovação-Lato Sensu, 1(1), p. 41-48.

Holanda, E. C., Verde, R. M. C. L., Neto, J. A. de O., \& Soares, L. (2020). Caracterização epidemiológica e prevalência de esquistossomose no Estado do Maranhão, Brasil. Research, Society and Development, 9(8):e735986622. https://doi.org/10.33448/rsd-v9i8.6622

IBGE. (2010). Instituto Brasileiro de Geografia e Estatística. Atlas do censo demográfico Bacuri - Maranhão. Rio de Janeiro.

Lima, C. D., de Andrade, D. S., Moreira, G. da C., Lima, C. A. S., Sousa, Â. A. F., Sousa, R. L. S., Leal, A. de S., Rêgo, N. da C. S., \& Rocha, J. A. (2021). Schistosoma mansoni no Maranhão entre 1997 e 2019: uma prospecção tecnológica e científica. Cadernos de Prospecção, 14(1):169. https://doi.org/10.9771/cp.v14i1.34725

Lira, M. G. S., Miranda, G. S., Rodrigues, J. G. M., Nogueira, R. A., Gomes, G. C. C., \& Silva-Souza, N. (2017). Ocorrência de Schistosoma mansoni no município de São Bento, Baixada Ocidental Maranhense, estado do Maranhão, Brasil. Rev Pan-Amaz Saude [online].8(4):45-51. http://dx.doi.org/10.5123/s2176-62232017000400009

Mendes, M. F. C., Ribeiro, D. M. L., Melo, B. O., \& Bomfim, M. R. Q. (2017). Investigação epidemiológica da esquistossomose mansônica em municípios do Maranhão, Brasil. J. Modelo Geospat, [s.1.], 2(3):12-18. http://dx.doi.org/10.22615/2526-1746-jgm-2.3-6851.

Mendes, R. J. de A. (2019). Análise temporal e espacial da esquistossomose mansoni no estado do Maranhão no período de 2007 a 2016.78 f. Dissertação (Programa de Pós-Graduação em Saúde e Ambiente/CCBS) - Universidade Federal do Maranhão, São Luís.

Nascimento, I. M. E., \& Meirelles, L. M. A. (2020). Análise do perfil epidemiológico da esquistossomose no Nordeste do Brasil. Research, Society and Development, 9(11):e58591110022. https://doi.org/10.33448/rsd-v9i11.10022

Nogueira, R. A., Lira, M. G. S., Miranda, G. S., Rodrigues, J. G. M., Gomes, G. C. C., \& Silva-Souza, N. (2016). Distribuição dos moluscos transmissores da esquistossomose no município endêmico de são Bento, maranhão, brasil. Revista de Patologia Tropical / Journal of Tropical Pathology, [S. l.], 45(3): 295304. 10.5216. https://pesquisa.bvsalud.org/portal/resource/pt/biblio-913278

Maranhão. (2003). Zoneamento Ecológico Econômico do Maranhão. Fundação Sousândrade de Apoio e Desenvolvimento da Universidade Federal do Maranhão/Departamento de Oceanografia e Limnologia - DEOLI/Núcleo Geoambiental - UEMA: São Luís (MA). 252p

Maranhão. (2001). Zoneamento Ecológico Econômico do Pólo Ecoturístico Floresta dos Guarás. Fundação Sousândrade de Apoio ao Desenvolvimento da Universidade Federal do Maranhão. 286p.

Mochel, F. R. (1999). Caracterização Espectral e Mapeamento dos Manguezais por Sensoriamento Remoto na Bacia de Turiaçú, Maranhão, Brasil. Tese de Doutorado. (1 ${ }^{\circ}$. ed.) Universidade Federal Fluminense, Rio de Janeiro: [s.n]. 126 p.

Mochel, F. R., Cutrim, M. V. J., \& Gueiros, B. (2000). Potencial dos manguezais da Baía de Turiaçu para o desenvolvimento do ecoturismo na Amazônia Maranhense. Indicadores sócio-ambientais. VI Encontro Nacional de Educação Ambiental em Áreas de Manguezal, Parnaíba. In: Resumos do VI Encontro Nacional de Educação Ambiental em Áreas de Manguezal. v.1. p.74 - 74. ISBN: 978-85-61498-08-5

Pinheiro, I. S., Higino, T. M. M., de Souza, D. C. P., \& Aliança, A. S. dos S. (out/dez 2020). Prevalência de esquistossomose mansônica em comunidades da zona rural do município de Palmeirândia-Maranhão. Diversitas Journal, 5(4):2959-2971. https://doi.org/10.17648/diversitas-journal-v5i4-1264

Rabello, A. (1997). Diagnosing schistosomiasis. Memórias do Instituto Oswaldo Cruz. 92:669-676.

Ramos, M. C., da Silva, D. C., \& Silva, S. L. C. (2007). Educação, saúde e meio ambiente: o caso da esquistossomose no município de Itororó-Ba. Rev. Saúde Com., v. 3, p. 70-76, 2007. https://periodicos2.uesb.br/index.php/rsc/article/view/111 
Research, Society and Development, v. 10, n. 14, e129101421708, 2021

(CC BY 4.0) | ISSN 2525-3409 | DOI: http://dx.doi.org/10.33448/rsd-v10i14.21708

Santana, K. T. de O., Kayo, V. T. P., Pereira, V. V., Rodrigues, L. P., Ferreira, J. V., Oliveira, K. N., Trindade, M. J. F., Oliveira, H de., da Silva, E. S., \& Lopes, D. de O. (2014). Ocorrência de esquistossomose em Divinópolis-MG baseada em estudo com escolares e em inquéritos de notificação da doença. $J$. bras. patol. med. lab, p. 265-271. https://doi.org/10.5935/1676-2444.20140025

Santos, A. de M., \& Melo, A. C. F. L. (2011). Prevalência da esquistossomose num povoado do Município de Tutóia, Estado do Maranhão. Revista da Sociedade Brasileira de Medicina Tropical, 44:97-99. https://doi.org/10.1590/S0037-86822011000100021

Silva-Souza, N. da., Silva, A. P. de C. da., Oliveira, R. M. de., Lira, M. G. S., Nogueira, R. A., Penha-Silva, T. A. da., Melo, S. de A., Andrade, F. H. E. de., Santos-Ribeiro, L. S. dos., Neta, A. V. de C., \& Abreu-Silva, A. L. (2019). Parasitological and histological aspects of Holochilus sciureus naturally infected by Schistosoma mansoni. Revista Brasileira de Parasitologia Veterinária, 28:769-772. https://doi.org/10.1590/S1984-29612019075

Silva, R. D. M. de A., Neto, A. M. A., \& Silva, E. P. da. (2021). O uso do praziquantel no tratamento da Esquistossomose no Município de LimoeiroPE. Revista Multidisciplinar em Saúde, 2(1):98-98. https://doi.org/10.51161/rems/921

Soares, D. de A., Souza, S. de A., Silva, D. J. da S., Silva, A. B., Cavalcante, U. M. B., \& Lima, C. M. B. L. (nov 2019). Avaliação epidemiológica da esquistossomose no estado de Pernambuco através de um modelo de regressão beta. Arquivos de Ciências da Saúde, [S.1.], 26(2):116-120. ISSN 23183691. https://doi.org/10.17696/2318-3691.26.2.2019.1302.

Souza, F. P. C., Vitorino, R. R., Costa, A. de P., Júnior, F. C. de F., Santana, L. A., \& Gomes, A. P. (2011). Esquistossomose mansônica: aspectos gerais, imunologia, patogênese e história natural. Rev Bras Clin Med, 9(4), p. 300-7.

Teles, H. M. S. (2005). Distribuição geográfica das espécies dos caramujos transmissores de Schistosoma mansoni no Estado de São Paulo. Rev Soc Bras Med Trop, 38:426-432. 